\title{
THE DIGI-IMAGE AGE AND THE ISSUE OF THE GENERICIZATION OF TRUTH IN THE CONTEXT OF COMPARATIVE RELIGION*
}

\author{
Ali Öztürk \\ Alanya Alaaddin Keykubat University, Antalya-Turkey \\ imajoloji@gmail.com \\ https://orcid.org/0000-0002-7810-3152
}

\begin{abstract}
With digitalism, humanity entered a new age-the digital metaphysical period. Significant distinctions from previous epochs mark this period. Indeed, digitalism produces a transformation in every field via its specified applications, resulting in the creation of a new natural cosmos and a new human species. Unarguably, in addition to all its productions, the field in which digitalism most excels, owing to its inherent nature, is the adoption of an imaginary state of being as a database. This field, which we might refer to as the digi-image, has a significant impact on fields that can be changed into imaginary productions, such as belief, mystification, value, and culture, as well as
\end{abstract}

This article is an updated version of the paper titled "Digital Human and the Problem of Genericization of Truth (Comparative Problem of Religion in the Context of Digi-Socialization)" presented at the "Digitalization, Values and Religion Symposium" held in Diyarbakır, Turkey in 2019.

Ilahiyat Studies p-ISSN: 1309-1786 / e-ISSN: 1309-1719

Volume 12 Number 2 Summer/Fall 2021 DOI: $10.12730 / 13091719.2021 .122 .226$

Received: September 28, 2021 | Accepted: November 15, 2021 | Published: December 31, 2021.

To cite this article: Öztürk, Ali. "The Digi-Image Age and the Issue of the Genericization of Truth in the Context of Comparative Religion." Ilabiyat Studies 12, no. 2 (2021): 185211. https://doi.org/10.12730/13091719.2021.122.226

This work is licensed under Creative Commons Attribution-NonCommercial-NoDerivatives 4.O International. 
the process of change in general. This study is a comparative and theoretical study of the new role that faiths, beliefs, and civilizations will play due to digital image transformation.

Key Words: Digi-image, digital society, digital belief, comparative religion, imagology.

\section{Introduction}

It is essential to characterize historical eras in terms of the types of knowledge or production methods that they are socially connected with. Indeed, social contract ideas have dominated the history of philosophy. Perhaps more critical than this is the Torah and the Bible being referred to as the Old and New Testaments, respectively. This demonstrates that combining people's periodic experiences with significant treatises is an old practice. Perhaps one of the most critical purposes of religions, cultures, beliefs, and social and political systems is to facilitate the formation of an acceptable, functioning, and legitimate contract environment. As a result, it is feasible to discuss several contract types that have affected social life in the past. Today, however, we are approaching, or have arrived, at a period when digital contracts govern our cohabitation arrangements. Discussion of digital humans or digital civilization has become an everyday occurrence. Indeed, digitization reveals a reality that transcends the use of a simple instrument in human existence. Humanity and civilization are both pushed into a new definition zone by digitalism, into a new range of social contracts, and compelled into metaphysical and ethical tales by a digital world.

Furthermore, man has not avoided the effect of religions, which construct the incentives for loyalty, morality, and spirituality that we perceive as decisive factors in the ancient tale and typological structure. However, conflict, competition, and incompatibility exist between the direction, severity, recommendations, and models of these religious activities and the digital universe's judgments in this field. It is also interesting how digitalism has a mystical component that manipulates the original religious suggestions and adapts them to new contexts. These trends, if not for all faiths, are believed to have resulted in new crises for Islam. Despite these difficulties, new prospects for iconoclasm and pagan faiths are arising (such as Christianity, Far East religions, and local beliefs and religions). When we examine the 
relationships between these faiths and the digital process, we see that they have a high level of mechanization in building effective methods for communicating their signals and unconscious meanings. Indeed, the presence of symbolic pagan culture and its constituents on a digital platform provides more convenient opportunities for a matter of reason. In contrast, it seems as if the Islamic religion, whose symbolism and symbolic prominence appear to be incompatible with digital platforms, is confronted with a new issue. Additionally, the fact that digital platforms and metaphysics are generated mainly in the Far East and the Christian world indicates different conditions.

This study examined how digitalism changes individuals and civilizations. Particular attention is given to human creative productions and how representations of religions and beliefs are reworked via digitalism. Because the digital world creates new opportunities for inventive productions, against this background, an attempt is made to comprehend the realities that faiths, particularly Islam, face in this new position. Paganism, Christianity, and Islam have all been called into question on a fundamental level by the potential of the digital era.

This study compares the present test of digital persons with religion and religions with digital people. The work has been incorporated into theoretical and retheoretical frameworks. Indeed, it is intended to achieve a new level of analysis and conceptualization via the techniques and capabilities of the field of "Imagology" and related disciplines. As a consequence, several solutions for the significant issues of the digital age are advanced.

\section{Digitalism and the Virtual Transformation of People}

Numerous studies on various elements of digitization have been published recently. More significantly, this process has a direct effect on all facets of human creation. In fact, the period's unique advantages do not stop with counting. However, there are grave misgivings regarding the direction in which this period has led individuals. These reservations are not delusory, however, because this is a process in which we can examine the outcomes in various ways and, more importantly, engage with the consequences directly.

Digitalization results in creating a new language, the destruction of culture and values, and an assault on human individuality through virtual reality. Many of these complaints, undoubtedly, center on the 
alienation created by digitalization. Indeed, although digitalism creates novel conditions in various fields, it is also considered a source of a new sort of alienation -which we might refer to as post-alienation-that manifests itself in every matter of life. There is a movement toward holistic, metamorphosis-based, and soft alienation-based forms of alienation. Because we may speak of a new type of individual and social fabric that are adaptable and coercive, yet convincing, transitions occur under the influence of narcosis, and all components of the hierarchical cycle can be replaced.

All classical arguments are metamorphosed; in this transformation, there are bytes instead of atoms, images instead of sights, brands instead of identity, consumption instead of culture, instrumental communication instead of human communication, and love and virtual pornography instead of love. Erotic fragmentation has undertaken a particular function that imposes metaphysical images on all objective processes. Solidity disappeared, but its influence began to spread, disperse, split and spread to many platforms. This also has turned all motives into obscure but efficient, undetectable concepts. As virtual reality becomes the new condition, everything has begun to lose its physicality by assuming virtual roles as excessively alluring yet instantaneously replaceable. At this point, shallow, dispersed, and square thinking patterns (screen-centered, rootless, immediate, changeable, inflexible, and limited) have started to predominate over holistic, disciplined, analytical, and in-depth thinking (Öztürk 2019).

No adventure is more significant than reality itself. Although the virtual world's inherent system generates highly charged experiences, it has not yet generated a reality as spectacular as the one that has driven humankind to its knees. In other words, despite the virtuality of the virtual environment, its outcomes have generated a human reality that is rather dramatic. Baudrillard and his contemporaries refute this assertion via novel terms such as transparency, hyperreality, and fractal pathology (Baudrillard 2011: 133). As a result, a novel and new, detached social revolution will be discussed (Baudrillard 2011: 187). Along with this, humankind did not spontaneously go on such an endeavor. The classical human (premodern human type) is intolerant for a variety of reasons. On the other hand, the way people work has made it hard to accept one another.

Thus, digitalism is a thick wall (metaphorically speaking) that people construct against one another; it is an accessible, immediate, fun, and function-centered environment in which individuals have an 
increased opportunity to intervene in their affairs. Even in this day and technology, it may be challenging to complete a reasonably basic transaction at a bank, and the abundance of harmful human queues is an added benefit. The sensation of securely carrying out tasks under a machine's leadership, without submitting to human whims, with command systems in the virtual world by adhering to a technological agreement is not, however, to be underestimated.

Now, it is evident why people adore gods rather than philosophy's pointless and boring analyses. Indeed, it is entirely understandable that the Islamic faith focused its criticism on paganism rather than on philosophical currents, except at the margins. Because paganism is like a digital playground, complete with persuasive, inclusive, and incredibly rich subliminal material, it is a playground in which the subject is missing, where human desires find a new shape in commodities and where all meanings are ambiguous.

In this practical field, it is possible to assert that paganism is superior to philosophy and that philosophy is often at its service. Of course, this is not a reference to philosophy's intellectual riches, its dizzying historical context, its quest for coherence, or its issues and dilemmas. The parallel here is about the limitations of the philosophical-human link and the immensely alluring human targeting of pagan dynamics. Indeed, philosophy has often been overcome by the enticing passion of paganism, sometimes joining the service of paganism and forming several peculiar and complex dogmas and gods. Additionally, philosophy amassed many pupils endowed with enlightenment's power, who would be submissive and stubborn in this matter. This kind of transformation reveals new shapes that might vary from period to period. ${ }^{144}$

This new digital revolution is not entirely self-contained inside this grand narrative. Because technological development infuses human transformation with a new ideological dimension (Habermas 1977), man imbues technical aspects with spiritual significance (Robins 1996: 41). With the instinct of in corporeality, the predominance of visual

144 Of course, we can think that these findings, which are very contrary to philosophy's daily and academic images, are shocking. To open a new front in the debate, it is possible to say briefly that critical philosophers are no strangers to these expressions. Popper, Feyerabend, Deleuze, Foucault, Habermas and similar philosophers had important discussions on this issue. Ali Öztürk's work titled Imajolojicontains broad criticisms, determinations, and suggestions on the subject. 
sense (Berger 1990: 21) results in a typology that finds existence apart from experience. These and comparable mechanisms rob the human experience of several facets. As a result, since the digital person is unaware that his life process provides him with vulnerability and is controlled, he is also impervious to any examination or critical signal. Confusing signals obliterate all forms of critique and structural mental activity. Due to the ferocity of the virtualization process, individuals have begun to seek the opposites of the values inscribed in them in the cyberspace productions they encounter. Indeed, the imaginary world created by the cyber field has had a matter on the human crucible of belief: It may be argued that it arranges its ontological and cosmological secrets periodically, not via revelation or wisdom, but through the cyber field's productions and following its instrumental expectations. Because the field of aliens, such as UFOs and similar components, that guides the evolution of the human race and even nature is nonsensical, it develops very efficient subconscious talents (Öztürk 2019: 274).

This virus first forms a recognizable picture in our brains via hundreds of instruments and specific film industry productions and then obtains credibility. Similar assertions are made in certain scientific films and are accompanied by arresting pictures culled from film stills to convince the masses. We are seeing the metamorphosis of these decorations, which significantly impact people's common sense and conceptual growth, into an information flow in which virtual visuals back up religious claims from legendary eras. Perhaps most significantly, everything is presented in a game-piece format. Authenticity and forgery are inextricably linked, and one may simply be substituted for the other. However, falsehood strikes and seriously harms the truth (Öztürk 2011: 106). For instance, any economically manipulative fiction or message has the potential to flip all markets on its heads and to affect those who interact with the real economy daily. This is a complex subject with several facets, ranging from political to psychological.

People's spiritual needs, and perhaps more crucially, their future plans, can be influenced by new types of fraudulent virtual market intermediaries. The Qu-post tales spawned a new generation of shamans. Quantum sisters subscribe communities and people to new healing metaphysics via sessions of transmitting good energy to the cosmos through social media, television, and other social platforms. Contradictions are prevalent in regard to analytical thinking styles, e.g.; 
Quantum sisters: "Send positive energy to the universe"!

I am perplexed, the fastest sending path in space is the speed of light, and energy can reach that speed.

If I send positive energy now, the nearest star (except the Sun) is four years away.

If it misses, this energy will go away for millions of years.

So when will he be back?

Here, it is a complete enigma because it can take billions of years.

The approach is not positive at all. Yes, all of life in this day is theatrical, but a large portion of it is more so. These instances look hilarious at first glance; they arise on digital platforms as effective mechanisms that shape people's daily lives, political and economic inclinations, provide erroneous, inconsistent, but effective metaphysical facts, and trade hope and destiny.

As Öztürk (2019: 247) notes, these and related events are explained by the idea of "foam awareness." This phenomenon, dubbed the foam consciousness level, possesses an imagist quality: the codes are founded on an emotional contract based on the acceptance of general information, symbolic sympathy, and imposition. While this is hugely destructive and choppy, it is also a transient and ironic state of affairs.

However, the following is necessary for a judgment process based on analysis, virtue, and wisdom:

- a good and common-sense approach,

- staying true to knowledge and truth,

- maturity,

- to be fully aware of listening to the parties and their approaches,

- making goodwill essential in understanding, considering the possibility of misunderstanding,

- an understanding of the kind that is not confined to our own experiences, passions, and traumas,

- keeping all our faculties and sensory channels open to understanding. The phenomenon of digitalization in question perceives all judgments through symbols and images that have been 
sabotaged through new image conventions. On the other hand, common-sense inquiry pays attention to factors such as:

- Misunderstandings caused by tools,

- Misunderstandings caused by us,

- Misunderstandings caused by intermediaries and various centers, etc.

Naturally, with the networks of digital organizations, digitalization has gained a new dimension, including the digitalization of these advancements and their philosophical underpinnings. Digital organization, by its very nature, enables judgments to be made about offensive symbols wherever possible. This, along with numerous other consequences, is corrupted in those who are compatible and opposed and those who are exhausted and beaten; legitimacy and a drive to prefer deprivation over privacy. Thus, individual and social sharing is not energizing but instead resemble a tangled mohair thread knitted with deep traumas. Everyone loses because it does not transcend the reductionist confines of signs that are knitted together with imaginary faults that are discovered or lost. What is gained and lost when an individual's garden is stolen after years of creating a virtual garden on a website?

This virtual reductionism enables both the producer and the consumer to work more efficiently. As a result, it promptly and sufficiently arouses interest, necessitating the absence of another alternative, and it also precludes the formation of prospective alternatives or leads them to die. In this instance, sight has supplanted the hand, heart, mind, and all our other abilities. This path, which enables us to obtain fast-food (undigested and undigested, pansy judgments) judgments in the short term, results in significant psychological and social traumas over time. The foam-consciousness model, which takes these self-created traumas into account as a secondary indicator, sabotages damaging traumas. Even if these traumas are produced by foam trauma, they become chronic and schizophrenic due to the sign bombardment's persistence. In the face of these new and widespread pagan behaviors, paganist and iconic belief centers are powerless. Every day, in digital temples, disposable gods are recreated. Additionally, new avenues for iconistic (iconic) religions have been established. Numerous unconscious and suggestive semiconscious messages can thus be identified. On the one hand, the belief-centered "akaid" (belief system) pattern, founded on 
morality and value-centered Islam, can exist solely in the digital world through the "word," and the effect of practice is shrinking. On the other hand, his "speech" is open to manipulation in a variety of ways. All these points require rapid resolution.

\section{The Qu-Post Era and the Epistemology of Digital Human/Digi-Socialization}

The relevance of the connection between historical periods and contracts is stressed in the introduction. This paradigm can characterize humanity's contracts with excellent knowledge throughout three fundamental periods using a Western-centric epistemology.

1) Premodern period/Classical period

2) Modern Period

3) Qu-post Term (Öztürk and Emre 2020)

It is worth noting that although the primitive era (prehistoric and nonhistorical) and its characteristics are not included in the Western historical perspective's classifications of this time, they play a critical vertical role in influencing all subsequent periods. It merits particular attention, particularly considering pagan culture and its objectives for legitimizing the looting system. The ancient Greek phenomenon, which Western culture defines as a substance, has immanent and qualified original definitions. Of course, it would be absurd to assert that they gained the capacity to label people who are not themselves as barbarians simply via observation of the other. The issue here is inextricably linked to the ethnocentric and even more civil-centric (civilization-centric) suppression of historical delimitation zones. Essentially, a critical epistemic equation establishes the contrast between universal and globalized knowledge and, therefore, the urge to be imperial. Additionally, a scenario has emerged with another kind of deviation - an area of experience that is localized with the local area and where the pagan and ghetto are also current.

If we return to the classical definition range, when we examine the premodern period, the period of empires that it encompasses and which serves as their practical historical embodiment, it was critical that a local element, as a commodity or value, be deepened at the center's turning and possess a universal and superior cultural identity. Naturally, this method required a short depth and accumulation. The 
center was established to increase its qualification by bringing every new product discovered in the neighborhood to the center. Thus, any local aspect may find a home within a more significant identity. Organic and harmonic integrity is established throughout time as a result of the syntheses. This concept, which is entirely applicable to the Islamic experience (Öztürk 2011: 130), made sense throughout Rome's and Christianity's multiple grave crises. This did not occur in the contemporary age; the center was thriving in homogenizing all local components. While doing so, an imperative character was used as a reference point. Modernity melted all distinctions into a single pot and gave them a unifying aspect. While this has resulted in irreparable grief, it has also resulted in the formation of a unifying framework around a paradigm.

The Qu-post word coined by us -globalization, postmodernism, poststructural phenomena, and quantum- to name a few, is a conception that encompasses both theory and methodologies. Additionally, the term qu relates to digi-intellectualism, which alludes to the process of computerization. The Qu-post era has produced an environment conducive to developing narcissistic, pathoschizoid, virtual-clique-ghettoic human traits, which also mirror schizophrenia personality features that experts model using fragmented, unconscious signs (Öztürk 2020).

The Qu-post era saw the mass manufacture of various indigenous cultures and ideals using a plastic identity as a secondary production tool. These readily created and consumed ideals (Adorno 2001) obtain credibility via standardization in Western capitals (Doğan 2013: 120). Thus, a local element that became marketable due to globalization has been extensively changed, quantified, priced, and commodified as a necessary component of other processes, decoupled from its historical and spontaneous origins.

Along with this process, the tradition's cultural aspects were sanitized, packaged, confined, and imprisoned inside an instrumental and professional framework, particularly in the West. It has since been transformed into a museum piece. On the other hand, in non-Western civilizations, cultural aspects undergo fast alterations, being integrated with all contemporary reasoning and turning into a new role as a kind of commercial product. This is the period of humanity during which everyone was compelled to contribute to the phenomenon's existence. The great mirror is created by drawing all humanity into the laboratory environment. Its technological and meta-ideological infrastructure was 
supported by a natural-like virtual ecosystem (Öztürk 2020). This process has corrupted both tradition and modernity, resulting in the emergence of what we refer to as the Qu-post period. It is also feasible that this circumstance may pave the way for a new synthesis in the long term.

The classical era, particularly in the Eastern-Islamic world, established the leader - mass connection as virtue sharing and model offering. Today, the interaction between the leader and the masses (or any kind of leadership) takes the shape of a therapy-hypnosis spiral. An eager connection develops between the leader and the people, rather than an intellectual transfer or an emotional provocation. Rather than reason, reasoning, and enriching engagement, the processes of attraction, seduction, and consolidation take precedence. The person becomes a component of the feedback as an apparatus of the grand mechanism during the Qu-post era. People become an unconscious component of the system's evolution, even if it is to the system's harm. All digital technologies are modularized in response to customer input. Additionally, the customer has become the platform's capital. Through training and recommendation, experts exploit this capital. The behindthe-scenes or hardware and software phases are very methodical. At the same time, production and outputs are chaotic and caught in a highly metaphorical or semi metaphorical quandary, specifically hardware and software for Kant and Hegel and output and product for Nietzsche and Sartre. In summation, philosophers who advocated for system mechanization contributed to the equipment of this digital structure, while philosophers who engaged in speculation, rhetoric, and aggressive metaphors provided advertising and display boards.

A contradictory language has started to pervade all modes of communication and connection. A fundamental language coding system has formed that is inconsistent, rootless, ironic, symbolic, and arbitrary. Era-specific conceptualizations will likewise have to be this way throughout this period. Indeed, throughout the qu-post-digimagical era, professionals cultivated a narcissistic, pathoschizoid, virtual-clique-ghettoistic personality feature that takes on schizophrenia characteristics via fragmented unconscious signs (Öztürk 2017). Yes, this human species is fueled by new technology, affecting future generations by arresting themes such as superhumanposthuman, endless cycle, desire for power, nihilism, evolution, education, asceticism, development, biodevelopment, morality, suffering, sadness, longevity, and immortality (Dağ 2018). However, it 
is primarily sustained by the world's crises of metaphysical turbulence and humanization recessions. This method is heavily influenced by worldwide postmodern thinking and behaviors (Küçükalp and Çevirici 2018).

Believing technology has a self-evident objective nature and naïvete (Heidegger 1977: 4). Subliminal symbolic phenomena market shopping is holy in the digital visionary mutashäbihāt age. Because anybody has the right to shop, is it the case? For instance, can a person believe that when shopping, he or she may freely pick an outfit that fits him or her? That election has been depicted before in exhibitions, ads, television programs, and other forms of media. Could it not be that a decision had already been made in numerous sign temples that formed in one's unconsciousness? Are our preferences woven into the fabric of other looms? Is it not true that our anger, love, body, and spirit are constantly being updated? Traditional societies, on the other hand, conducted business according to their disposition and sect. Specific options were explored via experimentation, generally with a commitment to classic collectivism, but the person was given a chance to reflect on facts, procedures, beliefs, and the ability to choose.

However, there is no presentation-adaptation connection that relies on initial values and can be examined with confidence intervals using specific values and items. Our naive mechanism of existence has been transformed into multipleschizophrenic flexible patterns, with a heap of instrumentalized ore that has become highly complex. Its motivations and value triangulations have become blurred, and the principles it serves and the application outputs are inextricably linked. Thus, we have succumbed to indecision and developed abnormal reflexes as a result of the obsessive pendulum. Indeed, when the model version evolves, the individual's duties and goals may shift as well. In a state of estrangement, we have indicated that the imagist theory of alienation allows for various sorts of alienation (Öztürk 2019). However, this kind of alienation is atomized on the ground, resulting in an infinite number of combinations (the interaction and displacement of the variables here are not only horizontal but also vertical and deep; that is, the displacement of the eyes is not enough, but the toenail and the eye can be displaced as well; moreover, the nail can reach gastronomic pleasure apart from attaining the sense of sight). It is a distinctive kind of alienation that has developed into an instrument, but its premise may also be instrumental (Öztürk 2019). 
In a novel process, images and symbols have acquired numerous meanings (Eliade 1961) in what is the commodification of symbols (Wernick 1996). The commodity's symbolization has taken on new shapes. Since the communication phenomenon, as defined by classical assumptions, has evolved significantly from the primary helix of the conveyer, the message, and the transmitted (Açıköz 2017) (Mcluhan 2011), people today find shape in pools designed by professional hands, regardless of whether these professionals are patented or pirated. Every religious system, society, and interest group on the planet supports this human type in one way or another, willingly or unwillingly. This kind of individual is suicidal. Perhaps a remedy is achievable by honestly defending, modeling, implementing, and changing authentic value-based human relationships. We discuss a breakup, a scenario that cannot be dismissed based only on rhetorical, romantic, or everyday terms.

The internet platform alienates individuals in their real and personal relationships and might sometimes exhaust their desires and dreams. Thus, there is an appealing aspect as well. In a communication platform based on pure unmanned messages created without an interlocutor, both parties may experience pain and fury at times, or both parties may be tricked with virtual and unrequited joy at times. It is a way of looking at life, analogous to a peculiar "deception" game that begins with itself. As a result, the message might become a component of conflict and posturing rather than a component of communication. The internet world is an intriguing plant of irony, with its qualities that you cultivate in your jar yet direct toward another person. When political and religious concerns are involved, the coefficient of this pathological curve might have geometric repercussions. This plant can transform an unimportant actor into a sociopsychological predictor of significant issues. This is a perilous state of affairs, a disease that both producers and consumers should be aware of.

In this setting, a new situation has developed in which we cannot explain digital dictatorship's determination (Harari 2016). We need new conceptions of digital identity that go beyond the definition of digital footprints since this texture reshapes individuals. Each of us has a digital identity account, like our virtual bank account, and we effectively amass our personality in the digital realm as well. Additionally, although our funds were held in the bank in classical life, we now have a new kind of creation that our personalities have 
grabbed and sold to us, transforming it into blackmail. This is a critical matter. First, let us consider the conditions in which our personality may exist.

It is possible to list the main risks in terms of the shape that the digital world has taken over our identities, as follows:

a. Superficial and shallow consciousness

b. Exhibitionist identity

c. Ego and hedonism vortex

d. Symbolic and reductionist episteme

e. Disposal existence (a form of "throw-away" production of identity, belief, judgment, and similar vital principles)

f. Post alienation; Digi-alienation

g. The flood of manipulation, deception, and manipulation

h. Active and variable addiction, chronic negligence and pathology, etc.

Perhaps as a continuation of this discussion, we will discuss a new process by which the cybernetic organism, as a new human species, emerges via a living and machine-informed design (Barrett 1999: 176177). In summation, although technology was unable to build a paradise for humans, it did succeed in producing its human beings. This natural process has a profound effect on every aspect of human beings in a variety of ways. Similarly, religion, belief, education, and values all affect and change several disciplines. We are confronted with processes whose future evolution is unknown. On the one hand, media outlets provide popular publications and content that contribute to establishing a global culture among people; on the other hand, national publications emphasize the relevance of local-national culture and values. In such a broadcast environment, clashes between localnational ideals and global identities are unavoidable, and people and organizations are subjected to a painful process of selecting between these two volatile environments (Nas 2019: 182). Indeed, subidentities, local identities, national identities, and global identities all exist. Apart from macro identity conflicts, marginal identities, the pressures of the new generation, and chaotic identities all find their way to their intended recipients in various ways. Additionally, we lack any filtering or interface protection, which means that these assaults will intensify. 
In a literal sense, this is a new sort of epistemic jetlag. This multidimensional catastrophe requires immediate examination. These procedures are briefly considered.

\section{The Genericization of Truth (Comparative Religion Matters in the Context of Digi-Imaginary Socialization)}

Is truth a well-guarded secret? How is it comprehended? What is the difference between truth and fact? Why did the man go on such a journey? What is the answer to this issue at this point in human history in terms of religion and culture? These and other questions might be raised concerning this multifaceted subject. Indeed, by resolving these and similar problems, civilizations, philosophy, science, and all human creations, most notably religions, affect our existence. The path to truth must pass via several persuasive channels. However, it is adamant about being seen with human eyes. Indeed, the tale of Prophet Moses clearly expresses this. This concept is equally effective in expressing the fine line that separates Christianity, Islam, and pagan faiths.

When Moses came to the place appointed by Us and his Lord addressed him, He said: "O my Lord! show (Thyself) to me that I may look upon thee." God said, "by no means cans thou see Me (direct); but look up on the mount; if it abide in its place then shalt thou see Me." When his Lord manifested his glory on the mount, He made it as dust, and Moses fell in a swoon. When he recovered his senses, he said, "Glory be to Thee! To thee, I turn in repentance, and I am the first to believe." (God) said, "O Moses! I have chosen thee above (other) men by the mission I (have given thee) and the words I (have spoken to thee): take then the (revelation) which I give thee and be of those who give thanks." (Q 7:143).

God indeed heard the voice of all people via the prophet Moses. Because man is a visual entity, all men by nature desire visuality to perceive. This is a more compelling incentive than Aristotle's finding that "Man inherently desires knowledge (All men by nature desire to know)" (Aristotle 1996). Finally, individuals believe what they see to be more dependable than what they know. It is no accident that many philosophical, scientific, and contemporary perspectives get their legitimacy from this drive. However, the eye has lost its innocence (Kearney 1988: 2).

It is necessary to see, yet it is also deceptive. Since sight is a tremendous deception, the Israelites chose the golden calf of Samira to 
the God of Moses in this fashion. This tension has shaped human history. Because God declined to make a direct appearance, it would not be an exaggeration to assert that this tension is a significant factor in the evolution of civilizations. For, just as God dropped into man's heart, he was pictured as coming into being via his hand. The God, who is poured into pictures, signs, symbols, paintings, sculptures, and carvings and who does not fit on the mountain, has been constructed in a reductionist manner by human hands everywhere. Perhaps a reductionist feature of the "Allah is the Light of the skies and the earth" metaphor laid the groundwork for another manipulation opportunity on this occasion. Because man can define God any way he likes, based on his image, prejudice, practice, and interests, rather than on God's projections. There are several options for such a course.

Indeed, there is no distinction in terms of God's notion between Islam and paganism. Although Islam emphasizes a superimage (beyond-image) belief system and a news-centered view of God, other belief systems have built a belief system based on God's image, symbol, and experience projections. This perspective has imbued all human pursuits with a unique impetus. In miniature architecture, music, everyday life, and all other areas, there is a unique metasystematic process that we may trace. However, it is recognized that diverse orientations have resulted in a plethora of distinct options for the Christian experience.

A similar incident is mentioned in the Bible as follows: (18) Moses said, "Please. Let me see your Glory" (19). GOD said, "I will make my Goodness pass right in front of you; I will call out the name GOD right before you. I will treat well whomever I want to treat well, and I will be kind to whomever I want to be kind" (20). GoD continued, "However, you may not see my face. No one can see me and live" (2123). GoD said, "Look, here is a place right beside me. Put yourself on this rock. When my glory passes by, I will put you in the cleft of the rock and cover you with my hand until I have passed by. Then, I will take my hand away, and you will see my back. However, you will not see my face" (Bible-Exodus-33: 18-23.

Indeed, these two terms exemplify the distinction between Islam and Christianity. It expands the realm of possibilities, particularly in terms of digitally instrumentalized ideals and beliefs. While the Qur'an does not submit God to any image or epistemology, Christianity has brought the notion of God incredibly close to paganism, or at the very 
least, adapted it to the Roman representation and human form systematics.

Öztürk (2019: 87-90) tried to explain this issue as follows: Understanding the difference between worshiping something and worshiping depends on solving epistemic confusion. Many anthropologists accepted the projection of idolatry as synonymous with worship and offered a reductionist account of the genesis of religions and beliefs. For instance, it is natural for humans, who are more connected to nature than evolutionists, to worship a symbol that represents a natural element. What about the religious act? How did they come to do such an unnatural act? Additionally, at a period when they are just starting to deviate from nature. In this sense, the embodiment of symbols, deeds, convictions, and beliefs generated by a plane that transcends the width-length-depth ratio is sacred. The channel and production connection provides a world of possibilities for imagist knowledge as a distinct debate subject.

The issue may be discussed in terms of belief systems. We might consider the Christian world's contribution to the junction of the imagist and holy space by introducing God, whom Plato viewed as an idea issue (this is a superior level), to the agenda with a motive based on the perception of the icon unique to Rome. In Islamic culture, God is not actually contained inside a picture or emblem; instead, it is a question of faith. As a result, there is no discipline of study dedicated to God's sculpting. God, on the other hand, is the shaper. As a result, the preceding approach came face to face with a religious perspective oriented toward the person and centered on the mode of connection with God. The technical distinction between channels and production may be seen here.

Christianity advocated a God based on a group and center structure in this manner. The symbol has attempted to create a secondary signifier based on affiliation and registration. In other words, there is no individual attachment if you are an iconologist and experience God as an icon. This creates a unique position for witnesses or those who qualify as witnesses. Thus, religious identification is only conceivable via affiliation with a recognized center and group. As a result, no one can become a Christian on their own. Christianity and mythology have expanded the number of doors that open to one another in this situation. When we get to the base of the dilemma, we notice that the first question that comes to mind is whether the God of philosophy is an invented God. Christianity developed this image of God into an icon 
over time. Clearly, the iconistic framework made it simpler to change the deity, which may be illusory. It is apparent from this that the Ancient Greek and Roman possibilities also had a significant role. However, there is no path from a belief-based view of God with a practically extinct image region ( mutashābih/allegorical) to an icon entirely founded on signification and understood via the connection of belief. As a result, most skeptical reflexes may suffer religious crises due to the inconsistencies encountered when attempting to move the coded God issue to the imagined plane. That is why both the God of philosophy and Christianity are always reformable and intervenable deities. Indeed, although Nietzsche's declaration, "Deity is dead," generates excitement in many groups, it is not unique since he had the Jews slaughtered prior to the Christian God. Additionally, efforts to assassinate the deity are a significant motivator in mythology and ancient cultures. This also illustrates a distinct parallel with the case of unjustly assassinating prophets.

Although it is difficult to reconcile the broad features of religions with the definitions of Islamic religious belief, the following table has been created to aid in comprehension. Because religions have structured ideas and practical counterparts for the average person, such as God, prophet, worship, and afterlife, this is a grave error, given the Eastern-Islamic world's preparedness. Religions and beliefs exhibit asymmetrical patterns in a variety of ways. The aim of using Islamic faith as a foundation for this research is to enable comparisons via this methodical approach. Because other faiths are not structured in the way Muslims believe, they are exceedingly complicated and ambiguous, with numerous characteristics that may vanish. As a result, the table below has been constructed to aid in the comprehension of the distinctions.

PAGAN AND LOCAL
ISLAM

\section{The Understanding (Concept) of God}

Uncertain, mystical, pagan, iconoclastic, polytheistic, etc.
It can become iconic, obscure, mystifying, producing institutional sacramental practices, polytheistic.
He is known by faith and knowledge, above (beyond) icon and image, unique and unique. Its properties are known, although its 
nature is not fully grasped.

\section{The Understanding of the Prophecy}

Self-Securities;

Leader, chief, king, sage, shaman, etc.

Poetry, mystification, magic, mystery, metaphor, and the words and visions of certain fictitious characters
If the witnessing saints are to be counted in the way we understand them, then Jesus is not the prophet but God in some manner. In the modern-day, popes are even more superior than Muslims' prophets since they can intervene and build the revelation. They are free to adjust their religion as they like.

\section{Understanding of revelation}

Revelation is a book written by witnesses (Biblical preface), not by gods to prophets, but by witnesses who wrote the account of God Jesus (McDowell 1977: 1-5). The halo may continue, and popes may compose a new Bible if they like; what occurred at the Nicaean Council was not a failure to locate the true Bible but a failure to comprehend Muslims. It is the beginning of the Christian faith's formalization. Indeed, the trinity was embraced as a fundamental concept there. It was completed by the Istanbul consul (for further details see Waardenburg 2011; Gürkan 2011). In other words, a few Gospels were selected and recognized as official doctrines at that location. This update may proceed. In other words, Christianity is a religion that allows for structural change at the discretion of the clergy. The Church of England, Protestantism,
The representative is chosen by God and sent to him by revelation.

Text/Letter sent from Allah to His Prophet and open to all humanity. 
Calvinism, and the plethora of religious institutional practices growing now are not coincidental. This cannot be explained just by present requirements but also by a condition relating to Christianity's institutional development.

\section{Form of Religion}

Meditative, relational and tribal, class and similar qualifications and limited acceptance and possibilities.
It is guaranteed inside the walls of the club and institution. For if you become a Christian, you risk being ejected from the faith. Based on centralized registration. It is restricted to the institution's functional area.
Whoever wants to believe and live according to their beliefs and values may do so without recourse to intermediaries or references. A particular group institution, for example. It is not a monopoly; you may be a Muslim alone on an island, whether you are a slave or a king; wherever, there are appropriate ideals and ways of worship.

\section{Belief \&Value}

Tribal and mainly formed

performances

based on kinship,

dense symbols,

and

contemplative

motions. The need for identity building, communitization, clique formation, and socialization, among other
Values at the initiative of institutions and clergy along with some values.
Genuine understanding of God, belief in the unseen, belief in what the prophets brought, open to everyone based on unprivileged values, faith, good deeds, avoidance of evil, belief in the afterlife, etc. 
things,

collectively

believing in the

same thing rather

than discovering

the truth.

It is practically irrelevant for believing in the digital era to locate meaning in connections such as those that link heart, virtue, responsibility and morality. The main form is representativeness, symbolic and fictitious packaging, circulation, flexibility to new technology, and adaptability to exotic and cryptic ceremonial concerns. Perhaps more noticeable and appealing are the rituals that promote hedonism and egoism or collect material for generalized extreme experiences that promote narcissism and masochism. On the one hand, religion is rationalized and reduced to reductionist rules on the virtual scientific platform; on the other hand, it acquires a character that thrills and attracts parties on pirated digital platforms via its very bizarre and marginalized manifestations. Now, we may speak about a sizable population of young people who believe religion can be established and announced as national holidays. In other words, religion has started to assume the shape of socioepistemic experiences that cater to our spiritual desires, rather than a motivating region based on the awareness and responsibility of the hereafter within the context of people's relationships with Mawlá (Protector).

The sociopolitical dynamics that create religion as a socioepistemic and ghetto or national apparatus are the origins of deism discussions that have recently evolved in Turkey and cannot be explained by philosophical considerations alone. Indeed, this consequence has resulted in replacing religious messages in social media with historical excitement celebrations and general self-confidence messages. In other words, values and traditions have been interpreted as a component, tool, and servant of our sociocultural, political, and ghetto roles (metaphysics and attitude determinations generated through narrow network relationships), and the marketing problem associated with these has completely transformed religion's mute and primary message, transforming it into a consumable, sociocultural tool. Additionally, religion as a symbolic consumption value in conflicts of interest has generated a symbolic distance against religion, particularly among younger generations, while religious supporters have transformed this position into a symbolic consumption debate. This 
has resulted in extreme religious activities and methods in places of social conflict (Öztürk 2011).

Historically, a wide variety of definitions of religiosity have been made. It is possible to talk about many definitions, such as mystical piety, air piety, common religion, esoteric piety, strict piety, moderate piety, loose piety, predecessor piety, marginal piety, destructive piety, răfid̄i piety, and hypocritical piety. All these are definitions and descriptions with certain validity. However, we would like to classify a few primary religious forms, taking into account the current developments:

a. Sectoral, institutional, and intellectual rationale holisticreductionist religion: Religion that is owned, produced and institutionalized through madrasah (university), theology, religious, and other organizations. It is the way religion combines several facets of life with its logical and intellectual frameworks and theory, practice, and modeling. It is founded on establishing an unbreakable connection between the spirit of the moment, social demands, and religion. However, it now risks becoming a speculative and intellectual activity on a variety of subjects.

b. Symbolic-emblematic-codified (forms coded across several networks) and sign-reductionist religion forms: The experience of religion in which religious symbols and arguments are instrumentalized and subjected to heated symbol warfare. A very beneficial mode of manufacturing in the digital era.

c. Religion as a fragmented, fragmentary, and sarcastic form: The quest for a holy manner of meditation, healing, and catharsis along religious lines, which is not uncommon in the errant lives of the new generation.

$\mathrm{d}$. The unhealthy and alienating type of religion compels people and communities to engage with religion to create a daily life connection resembling different psychiatric disorders.

e. Ghettos (forms that provide unity of perception and judgment on new networks that go beyond the classical community form are mentioned) Religion form: The aspect of religion that converts a person into a member of the religious group to which he belongs, as well as the way the religious group constructs 
perception, judgment, and practice via the use of its new networks.

f. Value-centered, humane, and moral forms of religion: In my opinion, the proper form of religion that was shown in the first emergence of Islam and that balances and normalizes the above forms of religion and finds meaning in values, humanity, and morality, presents a universal nature and form.

The stage manifested, explained, and arranged in the last article has an obvious dimension.

- A genuine understanding of God: one and only, creator, omnipotent, etc.

- A clear understanding of prophecy, announced through prophets, bringing news, etc.

- It is like the revelation that there is no possibility of open intervention by institutions and individuals with explicit and supra-human references.

- A precise individual and community expectation: striving for good and avoiding evil.

- There is an apparent belief in the afterlife, an awareness that everyone is responsible for everything they do, supracommunal, humane, and moral.

- The determination of knowledge and belief guarantees all ontological, cosmological, and human processes with a coherent and understandable scenario.

There is a textural mismatch between the value-centered, humanizing, ethically driven type of religion and contemporary digital technology. There is a lengthy and complex period of crisis in which a new accord between essence and value and symbolic transference must be reached. They often end up being diametrically opposed when conveyed in the representation of one another.

For this:

a. It is critical to maintaining a humanizing and moral kind of religion. Because most of these forms are a direct antidote to contemporary alienation, we shall be liberated from many of the difficulties we face today via worship, virtue, moral and multidimensional interaction with other people, all of which are practiced. Even five times daily ablutions and collective prayers may save individuals from addiction, associability, 
and a variety of other modern condemnations. Antiexhibitionism, modesty, infāq (donation), family and kinship myth, and dozens of other factors all contribute to the near impossibility of modern illnesses. Multiple instances are conceivable.

b. Existing technologies need Islamization, moralization, and humanization.

c. The hunt for cures for damaging technologies and products should be hastened. A significant portion of technologies are entwined with content and mechanizations that affect morality, family, and the human experience of cohabitation, and when we add weapons and technology that degrade the environment, we have a vast field. These must be addressed individually with new sensitivity.

d. Alternative Islamic, moral, and humanitarian technologies and products are being developed.

e. Faith, morality, decency, and a sense of human responsibility are required in the face of chaos. The digital era encompasses a plethora of ideas, attitudes, and behavior complexes whose origins, aims, and shapes are unknown.

Islamic civilization will face severe difficulties in the approaching era. The Muslim intellect, consistent with a sterile religious life and human connections, seeks knowledge and resolutions to specific difficulties. However, neither history nor life nor the future develops via sterile and restricted outputs. We are confronted with reality or virtual reality undergoing a fresh transformation that is exceedingly complicated and chaotic while remaining unpredictable. That is why we want theoretical, practical, and model outputs that strive to resolve chaos and confusion rather than techniques based on sterile recommendations. As a result, there is a strong demand for dynamic discourse and action operability that is context-aware, in addition to strictly systematic models. Naturally, value, humanity, and moral concerns should be the primary motivators in this process.

\section{Conclusion}

Digitization may be seen as a new era in human history in one manner or another. As the epistemological source of digitalization, image systematics, image clustering, image dynamics, and image burn, imaginary projections based on image epistemology (imagology) are precious resources. It is unimaginable that faiths and beliefs would 
pass through this process unaffected or without having an influence. However, not all faiths and religions anticipate the same kind of inquiries and responses. This, in turn, creates a new avenue for the imagined formation of symbolist and iconistic reductionist beliefs (Izetbegovic 1994), culture, and religions. There are new problems for Islam's religion, motivated by real-world reasons such as belief, value, morality, and virtue. However, in regard to Islam, it is recognized that there are specific, powerful reasons and behaviors against all sorts of alienation brought about by the digital age.

However, they must be evaluated on a multidimensional level. Otherwise, we will discuss either a model that is unrelated to the present or a belief system that has lost its identity due to the period's spirit. Although new opportunities emerge for pagan and radical symbolic identification beliefs, their symbolic creations may also be utterly split into digital fragmentation and incorporated into apparatus processes.

We cannot fix issues at their source in the mechanical and digitalized world since the source is unaffected by the problems. As a result, it is vital to build systems with value at the center in addition to solid alternatives. The digital platform is a manipulative platform, and it is dangerous to make judgments and continue without first detoxifying from its influence. As a result, many behaviors of old civilizations may be reformed to protect against constant digital attacks. It is a particular danger for decision-makers to create works with a more significant influence on life without building calm spiritual systems.

\section{DISCLOSURE STATEMENT}

No potential conflict of interest was reported by the author.

\section{FUNDING}

The author received no specific grant from any funding agency in the public, commercial or not-for-profit sectors. 


\section{REFERENCES}

Açıköz, Hacı Mustafa. 2017. İletişim Felsefesine Giriş. Ankara: Elis Yayınları.

Adorno, W. Theodor. 2001. The Culture Industry - Selected Essays on Mass Culture. London: Routledge.

Aristotle. 1995. The Metaphysics. Ogden, UT, U.S.A: Bayside Books. https://doi.org/10.1093/oseo/instance.00262329.

Barret, Michelé. 1999. Imagination in Theory. Cambridge: Polity Press.

Baudrillard, Jean. 2011. Simulacra and Simulation. Michigan: University of Michigan Press. 1998. The Consumer Society. London: Sage Publications.

Berger, John. 1990. Ways of Seeing: Based on the BBC Television Series, London: Penguin.

Dağ, Ahmet. 2018. "Nietzsche ve Transhümanizm Bağlantısı Üzerine Bir Değerlendirme." Felsefe ve Sosyal Bilimler Dergisi (25): 207-224.

Doğan, Mehmet. 2013. Hiperprestij Grupları. İstanbul: Neva Yayınları.

Eliade, Mircea, 1961. Images and Symbols. New York: Sheed \& Ward.

Gürkan, Salime Leyla. 2011. "Teslis.” In Türkiye Diyanet Vakfi Ansiklopedisi (DİA), XL, 549-552.

Habermas, Jürgen. 2005. "Technology and Science as Ideology." In Knowledge: Critical Concepts, vol IV: Politics and Knowledge, edited by Nico Stehr and Reiner Grundmann, 81-126. London: Routledge.

Heidegger, Martin. 1977. The Question Concerning Technology. New York: Garland Publishing.

Harari, Y. Noah. 2016. Homo Deus: A Brief History of Tomorrow, UK: McClelland \& Stewart Signal. https://doi.org/10.17104/9783406704024.

Bible (in Turkish) İncil (Sevindirici Haber). 1995. İstanbul: Ohan Matbaac1lik.

Izetbegovic, 'Alija 'Ali. 1994. Islam Between East and West, USA: Reprint.

Kearney, Richard. 1988. The Wake of Imagination. London: Routledge.

Küçükalp, Kasım and Sema Çevirici. 2018. "Kimlik ve Farklılık Tartışmalan Bağlamında Postmodern Düşüncede Temsil Eleştirisi” Felsefe Dünyası Dergisi 67: 5-32.

McDowell, Josh. 1977. More than a Carpenter. Illinois: Tindale House Publisher.

McLuhan, Marshall. 2011. The Gutenberg Galaxy. Toronto: University of Toronto Press.

Nas, Fethi. 2019. "Medyanın Siyasal ve Sosyal Etkileri." In İletişim ve Medya Sosyolojisi Yazılar, edited by Ümmet Erkan, 159-185. Ankara: Gece Kitaplı̆̆1. 
Öztürk, Ali and İsmet Emre. 2020. "The Crisis of Folkloric Heritage and Its Social Effects from Organic Doctrine to Postmodern Digital Policy”. Milli Folklor 16 (128): 153-162.

Öztürk, Ali. 2019. Imajoloji (Bir Disiplin Denemesi). $3^{\text {rd }}$ ed. Ankara: Elis Yayınlar1. 2011. Kriz Sosyolojisi: Batı Merkezciliğinin Yapısal Sorunları ve Kriz. İstanbul: Doğu Kitabevi.

. 2020. "Siber Küresel: Nano-İnsan, Sanalite Toplum ve Diji-Topluluklar (QuPost Pandemi Sonrası Dünya)." Çocuk ve Medeniyet Dergisi 5 (9): 55-71. https://doi.org/10.47646/CMD.2020.199.

Robins, Kevin. 1996. Into the Image: Culture and Politics in the Field of Vision. London: Routledge.

The Holy Qur’ān, 1968. Translated by Yūsuf 'Abd Allāh 'Alī. Beirut: Dār al-Qur’ān alKarīm.

Waardenburg, Jacques. 2011. "Teslis." In Türkiye Diyanet Vakfi İslâm Ansiklopedisi (DIA), XL, 548-549.

Wernick, Andrev. 1991. Promotional Culture: Advertising, Ideology and Symbolic Expression (Published in association with Theory, Culture E Society). Austin TX USA: SAGE Publications Ltd.

https://www.wordproject.org/bibles/kj/02/33.htm\#0. Accessed May 22, 2019. 